\title{
Effect of soccer footwear on landing mechanics
}

\author{
R. J. Butler' ${ }^{1}$, M. E. Russell ${ }^{2,3}$, R. Queen ${ }^{2,3}$ \\ ${ }^{1}$ Physical Therapy Division, Duke University, Durham, North Carolina, USA, ${ }^{2}$ Department of Orthopedic Surgery, Duke University, \\ Durham, North Carolina, USA, ${ }^{3}$ Michael W. Krzyzewski Human Performance Lab, Duke University, Durham, North Carolina, USA \\ Corresponding author: Robert J. Butler, PT, PhD, Doctor of Physical Therapy Division, Duke University, DUMC 104002, Durham, \\ NC 27705, USA. Tel: +919681 7225, Fax:+919684 1846, E-mail: robert.butler@duke.edu
}

Accepted for publication 13 March 2012

Lower-extremity injury is common in soccer. A number of studies have begun to assess why specific lower-extremity injuries occur. However, currently few studies have examined how footwear affects lower-extremity mechanics. In order to address this question, 14 male (age: $22.1 \pm 3.9$ years, height: $1.77 \pm 0.06 \mathrm{~m}$, and mass: $73.3 \pm 11.5 \mathrm{~kg}$ ) and 14 female (age: $22.8 \pm 3.1$ years, height: $1.68 \pm$ $0.07 \mathrm{~m}$ and mass: $64.4 \pm 9.2 \mathrm{~kg}$ ) competitive soccer players underwent a motion analysis assessment while performing a jump heading task. Each subject performed the task in three different footwear conditions (running shoe, bladed cleat, and turf shoe). Two-way analyses of variance were used to examine statistical differences in landing mechanics between the footwear conditions while controlling for gender differences. These comparisons were made during two different parts (prior to and following) of a soccer-specific jump heading task. A statistically significant interaction for the peak dorsiflexion angle $(P=0.02)$ and peak knee flexion angle $(P=0.05)$ was observed. Male soccer players exhibited a degree increase in dorsiflexion in the bladed cleat while female soccer players exhibited a three-degree reduction in peak knee flexion in the bladed cleat condition. Other main effects for gender and footwear were also observed. The results suggest that landing mechanics differ based upon gender, footwear, and the type of landing. Therefore, training interventions aimed at reducing lower-extremity injury should consider utilizing sport-specific footwear when assessing movement patterns.
Lower-extremity injury often occurs during sport participation (Marshall \& Guskiewicz, 2003). It is well understood that injury risk during sports is a multifactorial issue associated with intrinsic and extrinsic factors (van Gent et al., 2007; Myer et al., 2008; Barber-Westin et al., 2009; Goldman \& Jones, 2010). Sport-specific footwear has been constructed to reduce injury risk during sport and is typically developed to be unique to the tasks and demands of the specific sport. However, data are limited with respect as to how sport-specific footwear, outside the area of running, effects lower-extremity mechanics (Smith et al., 2004; Sims et al., 2008; Queen, Abbey, Wiegerinck, Yoder, Nunley, 2010, Hennig, 2011).

Differences in the characteristics of footwear have been associated with altering lower-extremity joint mechanics during running (Clarke, Frederick, Hamill, 1983; Hamill et al., 1992; deKoning \& Nigg, 1994; Perry \& Lafortune, 1995; Butler et al., 2006; Butler, Hamill, Davis, 2007; Cheung \& Ng, 2008; Kong et al., 2009; Morio et al., 2009; Sinclair et al., 2010; Wannop et al., 2010). Footwear research has traditionally focused on running because of the high level of the repetitive impact forces associated with the activity (Hamill et al., 1992; Butler et al., 2006, 2007; Cheung \& Ng, 2008; Kong et al., 2009; Morio et al., 2009), with a few studies examining jumping and landing (Brizuela, Llana, Ferrandis, García-Belenguer, 1997; Oliver et al., 2011). The results of these studies indicate that stiffer materials reduce the amount of frontal plane motion at the foot and reduce the lower-extremity impact shock while increasing lower-extremity compliance resulting in a reduction in the peak vertical ground reaction force (Clarke et al., 1983; deKoning \& Nigg, 1994; Brizuela et al., 1997; Kerdok et al., 2002; Butler et al., 2006; Cheung \& Ng, 2008; Kong et al., 2009; Morio et al., 2009). However, few studies have examined how footwear alters joint mechanics and the relevant movement-related injury risk factors during the sport-specific activity for which the footwear is designed (Brizuela et al., 1997; Smith et al., 2004; Sinclair et al., 2010; Wannop et al., 2010).

The effect of footwear on joint mechanics during jump landing may provide some insight as to the role footwear may have on injury prevention in sports. However, no studies exist that examine how landing mechanics are altered by differences in footwear that is commonly used in field sports. Therefore, the purpose of this study was to compare sagittal plane jump landing mechanics in three different footwear conditions (running, turf, and bladed cleat). These differences will be compared between two different types of landings (prior 


\section{Butler et al.}

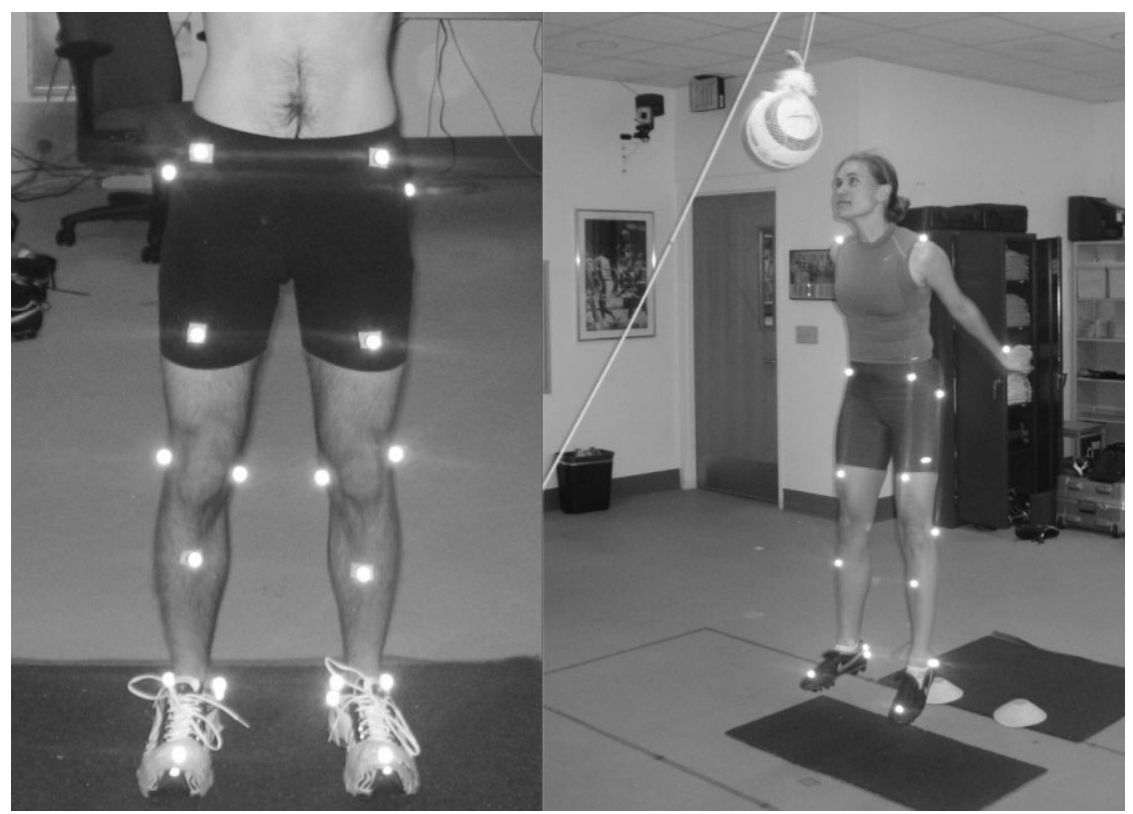

Fig. 1. Depiction of the marker set utilized for the study (anatomical marker set on left and tracking marker set on right).

to and following a soccer-specific jump heading task) to provide a more robust assessment of how footwear affects joint mechanics during different types of landings.

\section{Methods}

An a priori power analysis utilizing data from Brizuela et al. (1997) along with $\beta=0.20$ and $\alpha=0.05$ revealed that $11-13$ subjects need to be recruited per group to observe differences between footwear conditions. As a result of this analysis, 28 subjects (14 male and 14 female) were recruited for this study. The subjects ranged in age from 18 to 30 years. Fourteen female (age: $22.8 \pm 3.1$ years, height: $1.68 \pm 0.07 \mathrm{~m}$, and mass: $64.4 \pm 9.2 \mathrm{~kg}$ ) and 14 male soccer players (age: $22.1 \pm 3.9$ years, height: $1.77 \pm 0.06 \mathrm{~m}$, and mass: $73.3 \pm 11.5 \mathrm{~kg}$ ) were included in the study. Subjects who were included in this study had no history of lower-extremity injuries in the past 6 months, no history of anterior cruciate ligament reconstructive surgery within the past 3 years, were physically active and were currently playing soccer competitively. Being physically active was operationally defined as currently participating in some form of physical activity at least three times a week for approximately $1 \mathrm{~h}$ each time, while being a competitive soccer player was defined as engaging in practice or games at least two times per week. Each subject was asked to read and sign informed consent that was approved by the medical center's institutional review board.

Following informed consent, a series of measurements were obtained from each subject including height, weight, vertical jump height, foot width, and foot length. After measurements were taken, subjects were provided spandex shorts and a tight-fitting shirt to minimize marker movement that was not a result of anatomical displacement. Vertical jump height was tested using a Vertec (Jumpusa.com, Sunnydale, California, USA) device. The maximum height of three jumps using a two-feet take off was recorded for each participant. Maximum vertical jump height was used to normalize the height of the ball for the jump heading task. After completing the vertical jump assessment, a total of 24 markers were placed on each subject at the following anatomic landmarks: joint space between the fourth and fifth lumbar vertebrae (L4-L5), bilateral acromioclavicular joint, anterior superior iliac spine, greater trochanter, anterior thigh, lateral femoral condyle, anterior lower leg over the tibial ridge, lateral malleolus, posterior-superior heel, posterior-inferior heel, lateral heel, medial malleolus, medial femoral condyle, and an offset marker on the right scapula (Fig. 1). Following the placement of all of the markers, a standing static calibration was completed. Once the static trial was recorded, the four medial markers were removed and the subjects were ready for the dynamic jumping trials. Eight near-infrared cameras (Motion Analysis, Inc., Santa Rosa, California, USA) were used to record the trajectories of the 20 retroreflective markers at a sampling rate of $120 \mathrm{~Hz}$. The cameras were synchronized to two AMTI (Watertown, Massachusetts, USA) force platforms sampling at $1200 \mathrm{~Hz}$ to collect ground reaction force data. The eight cameras were placed symmetrically around the calibrated volume.

The dynamic jumping task that the subjects were asked to complete required that they were able to head a soccer ball. Subjects were asked to start at a position that was half of their body height away from the center of the force plate (Fig. 2). They were then asked to jump over a $7.5-\mathrm{cm}$ cone, which was placed halfway between the start position and the force plates, and to land with one foot on each of the force plates (first landing, dynamic landing). Astroturf (Ingrass, Eatontown, New Jersey, USA) was fixed to the top of the force platforms to improve the external validity of the protocol. The subjects were then instructed to jump up as quickly as possible and perform a jump header (the center of the ball was kept stationary and positioned above the head of the subject at $50 \%$ of the subject's maximum jump height) and then land back on the force plates (second landing, static landing). The first landing was identified as being dynamic because the landing was immediately followed by a jump while the second landing was determined to be static because no motion occurred following the landing. The jumping task was demonstrated for the subject and the subject was allowed a number of practice trials until they felt comfortable with the jumping task. No restriction was made on upper extremity or trunk motion during the trials and the subjects were encouraged to perform the task as naturally as possible. 


\section{Effect of soccer footwear on jump landings}

Three different shoe types (turf shoe, firm ground bladed soccer cleat, and a neutral-cushioning running shoe) were tested during this study (Fig. 3). The shoes tested were provided to the athletes at the time of the data collection and were not worn for any activities outside that or the experimental protocol. The turf cleat and bladed soccer cleat (Nike Vitoria, Beaverton, Oregon, USA) were made on the same last with different cleat plate configurations, while the running shoe that was used was a neutralcushioning running shoe (Nike, Air Pegasus). Because the cleated shoes were all built on the same last, the fit of each shoe was similar; therefore, the effect of accommodation time should have been minimal. The shoe testing order was randomized to remove any fatigue effects from the study. In addition, subjects were given at least a 30-s rest between each trial and a 2-min rest between each shoe condition. After the first shoe condition was completed, the shoes were changed, the medial markers and the shoe markers were placed on the subject again, and another static standing trial was recorded. Following the standing calibration trial, the jumping task was repeated. Five trials for each condition were averaged for each subject.

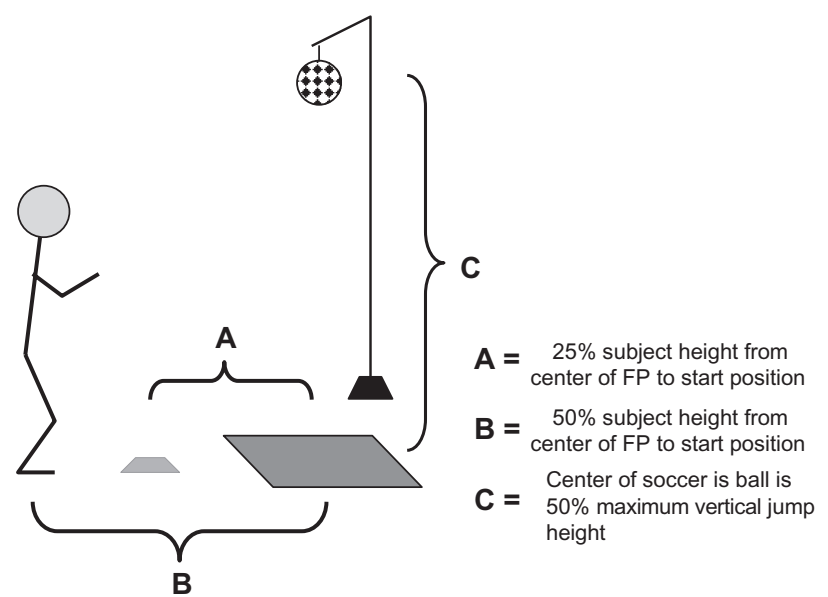

Fig. 2. Diagram of subject testing set-up (FP = force plate).
The variables of interest for the study focused on landing kinematic and kinetics during jump landings that have a primary role in limiting impact. The kinematic variables of interest were the peak lower-extremity angles (ankle, knee, and hip) in the sagittal plane. The kinetic variables of interest were the peak internal lower-extremity joint moments (ankle, knee, and hip) in the sagittal plane. Joint moment data were normalized to body height and mass. The peak hip extension moment was analyzed during the early portion of the stance phase and the late portion of the stance phase because of the bimodal nature of the curve. In addition to joint moments, the peak vertical ground reaction force was examined during the landings. The variables of interest were assessed for the first landing and for the second landing. Variables for the late stance portion were not analyzed for the second landing because this was the time when the individuals were returning to a stable upright position.

Statistical analysis was conducted utilizing Statistical Package for the Social Sciences (SPSS) software (SPSS v. 17, Chicago, Illinois, USA) to perform two-way analysis of variance (ANOVA; gender $\times$ footwear) to determine significant differences for all of the variables of interest. Separate two-way ANOVAs were carried out for the first landing and the second landing. An alpha level of 0.05 was established to identify statistical significance. Post-hoc tests were carried out using Tukey's honestly significant difference when statistical significance was obtained for the main effect of footwear. Effect size (ES) indices were calculated by subtracting the two mean values and dividing it by the pooled standard deviation.

\section{Results}

First landing (dynamic)

No significant gender by footwear interaction was present for either the peak dorsiflexion angle or the peak plantarflexion moment. There was a significant main effect for footwear for the peak dorsiflexion angle (Table 1, Fig. 4; $P=0.03$ ) and the peak plantarflexion moment (Fig. $4, P=0.02)$. The subjects had a larger $(2.1$ degrees, $\mathrm{ES}=0.38$ ) peak dorsiflexion angle in the blade (a)

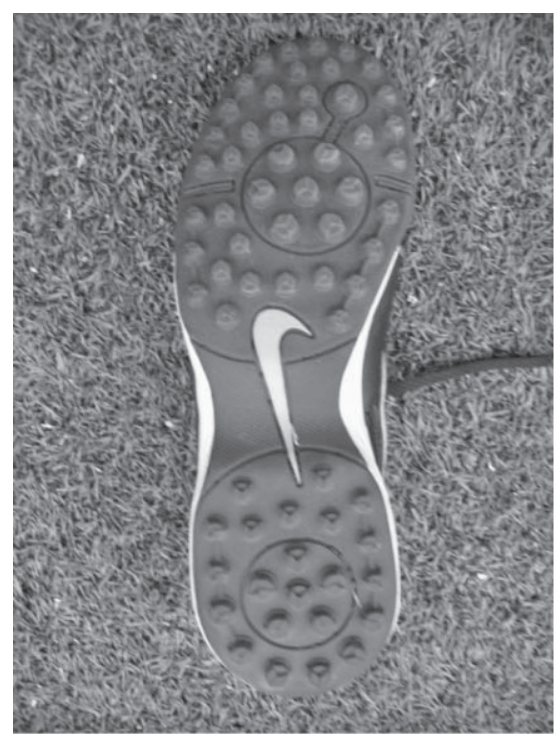

(b)

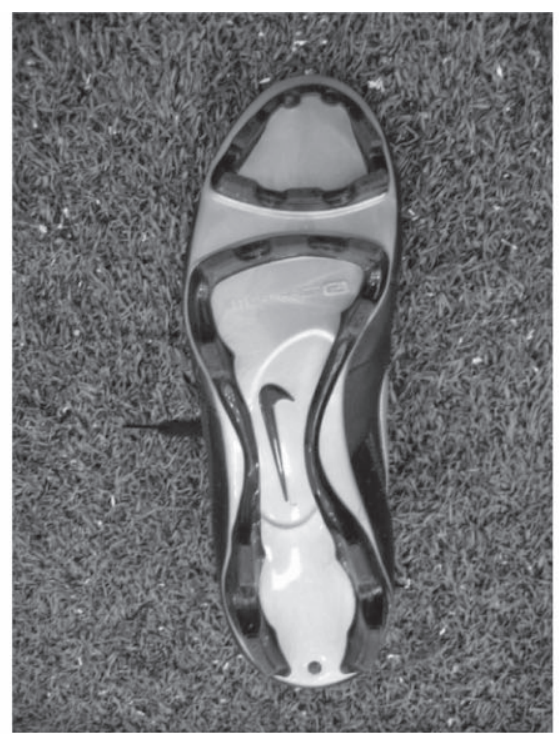

(c)

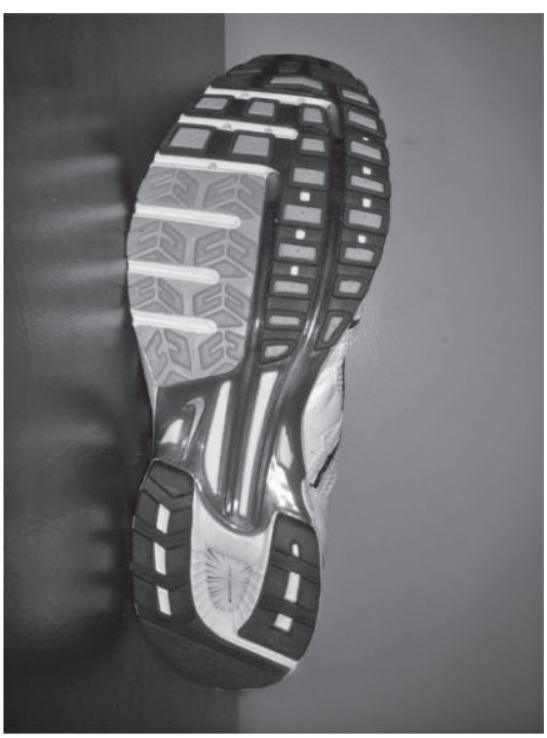

Fig. 3. Testing shoes: (a) turf shoe, (b) bladed cleat, and (c) running shoe. 


\section{Butler et al.}

Table 1. Descriptive statistics (mean \pm SD) for the variables of interest in male and female subjects wearing the different shoe conditions (blade, running, and turf) during the first landing

\begin{tabular}{|c|c|c|c|c|c|c|c|c|c|c|}
\hline & & \multicolumn{2}{|l|}{ Blade } & \multicolumn{2}{|c|}{ Running } & \multicolumn{2}{|l|}{ Turf } & \multicolumn{3}{|l|}{$P$-values } \\
\hline & & Mean & SD & Mean & SD & Mean & SD & Interaction & Footwear & Gender \\
\hline \multirow{6}{*}{$\begin{array}{l}\text { Peak dorsiflexion angle } \\
\text { (degree) } \\
\text { Peak plantarflexion moment } \\
\text { (N.m/kg.m) } \\
\text { Peak knee flexion angle } \\
\text { (degree) }\end{array}$} & Males & 26.3 & 5.8 & 23.7 & 5.5 & 21.8 & 5.1 & \multirow[t]{2}{*}{0.10} & \multirow[t]{2}{*}{0.02} & \multirow[t]{2}{*}{0.47} \\
\hline & Females & 23.8 & 5.8 & 24.1 & 6.4 & 24.1 & 5.5 & & & \\
\hline & Males & 2.06 & 0.39 & 1.98 & 0.35 & 1.97 & 0.39 & \multirow[t]{2}{*}{0.67} & \multirow[t]{2}{*}{0.02} & \multirow[t]{2}{*}{0.17} \\
\hline & Females & 1.85 & 0.45 & 1.73 & 0.44 & 1.79 & 0.49 & & & \\
\hline & Males & 73.5 & 7.4 & 74.8 & 7.3 & 73.7 & 7.4 & \multirow[t]{2}{*}{0.50} & \multirow[t]{2}{*}{0.09} & \multirow[t]{2}{*}{0.05} \\
\hline & Females & 67.6 & 7.5 & 69.1 & 7.4 & 69.0 & 7.4 & & & \\
\hline Peak knee extension & Males & 2.32 & 0.39 & 2.42 & 0.39 & 2.18 & 0.39 & \multirow[t]{2}{*}{0.41} & \multirow[t]{2}{*}{0.12} & \multirow[t]{2}{*}{0.09} \\
\hline moment $(\mathrm{N} \cdot \mathrm{m} / \mathrm{kg} \cdot \mathrm{m})$ & Females & 2.12 & 0.31 & 2.11 & 0.37 & 2.41 & 0.4 & & & \\
\hline Peak hip flexion angle & Males & 47.6 & 10.5 & 44.1 & 14.7 & 47.1 & 10.1 & \multirow[t]{2}{*}{0.61} & \multirow[t]{2}{*}{0.58} & \multirow[t]{2}{*}{0.05} \\
\hline (degree) & Females & 53.5 & 8.6 & 53.2 & 9.7 & 54.1 & 10.1 & & & \\
\hline Peak hip extension moment & Males & 2.62 & 0.92 & 2.55 & 0.61 & 2.81 & 0.82 & \multirow[t]{2}{*}{0.18} & \multirow[t]{2}{*}{0.62} & \multirow[t]{2}{*}{0.01} \\
\hline$(\mathrm{N} \cdot \mathrm{m} / \mathrm{kg} \cdot \mathrm{m})$ & Females & 2.04 & 0.61 & 1.95 & 0.71 & 1.91 & 0.62 & & & \\
\hline Peak vertical ground & Males & 1.94 & 0.33 & 1.82 & 0.31 & 1.93 & 0.31 & \multirow[t]{2}{*}{0.49} & \multirow[t]{2}{*}{0.14} & \multirow[t]{2}{*}{0.10} \\
\hline reaction force (BW) & Females & 1.72 & 0.37 & 1.68 & 0.36 & 1.69 & 0.34 & & & \\
\hline
\end{tabular}

BW, body weight; SD, standard deviation.
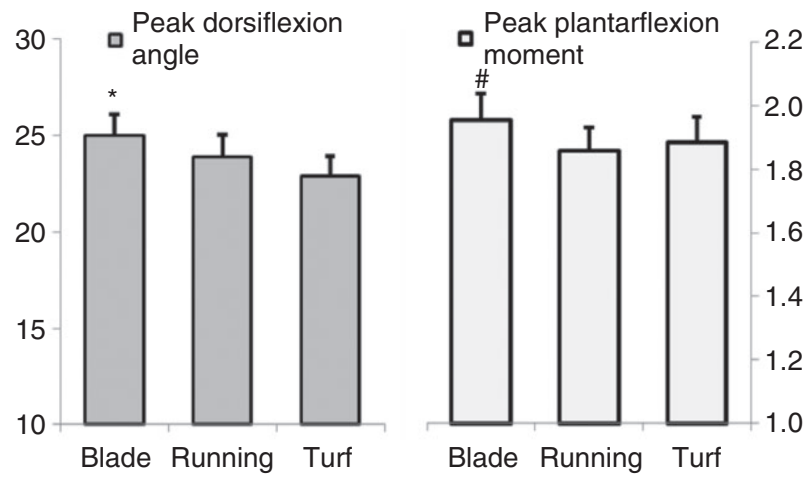

Fig. 4. Significant differences $(P<0.05)$ for peak dorsiflexion angle (degree) and peak platarflexion moment $(\mathrm{N} \cdot \mathrm{m} / \mathrm{kg} \cdot \mathrm{m})$ between the footwear conditions during the first landing (mean \pm standard error of the mean, * indicates blade cleat $>$ turf cleat, \# indicates blade cleat $>$ running shoe).

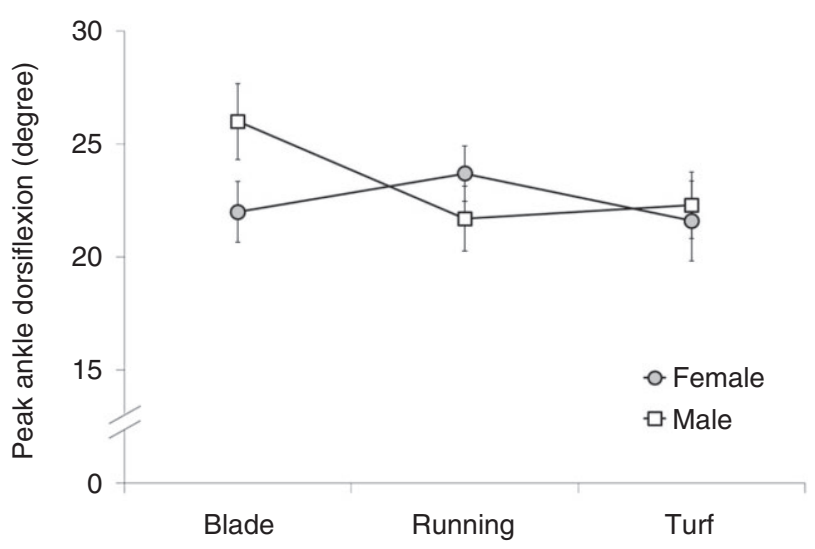

Fig. 5. Interaction of footwear and gender on peak ankle dorsiflexion during the second landing (mean \pm standard error of the mean). soccer cleat compared with the turf soccer cleat. Subjects exhibited a greater peak plantarflexion moment in the bladed soccer $(5.3 \%, \mathrm{ES}=0.24)$ cleat compared with the running shoe. No significant main effects for gender were observed for either of the variables of interest at the ankle.

Similarly, at the knee, there was no significant interaction between footwear and gender. There was, however, a main effect of gender for the peak knee flexion angle (Table 1, $P=0.05$ ) but not for the peak knee extension moment $(P=0.09)$. Female subjects exhibited a 5.4-degree $(\mathrm{ES}=0.72)$ decrease in peak knee flexion compared with the male subjects. There were no significant main effects for footwear for the variables of interest at the knee.

There were no significant interaction for any of the variables of interest at the hip; however, there were main effects observed for gender. Female subjects exhibited a greater amount of peak hip flexion than the male subjects (Table 1, $P=0.05$, ES $=0.70$ ), and exhibited a significantly lower $(P<0.01, \mathrm{ES}=0.97)$ peak hip extension moment during the late part of landing. No main effects were observed between the footwear conditions for the variables of interest at the hip.

No interactions or main effects were observed for the vertical ground reaction force. The maximum effect size differences for footwear were 0.38 while the effect size difference for gender was 0.67 .

\section{Second landing (static)}

There was a significant gender by footwear interaction for peak dorsiflexion angle (Table 2, Fig. 5, $P=0.03$ ). The male subjects landed with greater peak dorsiflexion in the bladed soccer cleat than in the running shoes or turf soccer cleat; in contrast, the female subjects exhi- 
Effect of soccer footwear on jump landings

Table 2. Descriptive statistics for the variables of interest for male and female subjects wearing the different shoe conditions (blade, running, and turf) during the second landing

\begin{tabular}{|c|c|c|c|c|c|c|c|c|c|c|}
\hline & & \multicolumn{2}{|l|}{ Blade } & \multicolumn{2}{|c|}{ Running } & \multicolumn{2}{|l|}{ Turf } & \multicolumn{3}{|l|}{$P$-values } \\
\hline & & Mean & SD & Mean & SD & Mean & SD & Interaction & Footwear & Gender \\
\hline \multirow{6}{*}{$\begin{array}{l}\text { Peak dorsiflexion angle } \\
\text { (degree) } \\
\text { Peak plantarflexion moment } \\
\text { (N.m/kg.m) } \\
\text { Peak knee flexion angle } \\
\text { (degree) }\end{array}$} & Male & 26.1 & 6.3 & 21.7 & 5.4 & 22.3 & 5.5 & \multirow[t]{2}{*}{0.03} & \multirow[t]{2}{*}{0.16} & \multirow[t]{2}{*}{0.62} \\
\hline & Female & 22.1 & 5.1 & 23.7 & 4.6 & 21.6 & 6.7 & & & \\
\hline & Male & 1.91 & 0.34 & 1.91 & 0.31 & 1.78 & 0.26 & \multirow[t]{2}{*}{0.88} & \multirow[t]{2}{*}{0.21} & \multirow[t]{2}{*}{0.07} \\
\hline & Female & 1.71 & 0.47 & 1.71 & 0.31 & 1.64 & 0.29 & & & \\
\hline & Male & 54.1 & 7.2 & 54.4 & 7.1 & 54.1 & 6.8 & \multirow[t]{2}{*}{0.05} & \multirow[t]{2}{*}{0.03} & \multirow[t]{2}{*}{0.34} \\
\hline & Female & 48.2 & 12.8 & 53.1 & 9.2 & 51.3 & 10.8 & & & \\
\hline Peak knee extension & Male & 2.01 & 0.53 & 2.01 & 0.59 & 1.93 & 0.47 & \multirow[t]{2}{*}{0.58} & \multirow[t]{2}{*}{0.38} & \multirow[t]{2}{*}{0.01} \\
\hline moment $(\mathrm{N} \cdot \mathrm{m} / \mathrm{kg} \cdot \mathrm{m})$ & Female & 1.43 & 0.52 & 1.57 & 0.39 & 1.46 & 0.54 & & & \\
\hline Peak hip flexion angle & Male & 31.5 & 12.7 & 30.2 & 12.7 & 32.1 & 12.4 & \multirow[t]{2}{*}{0.59} & \multirow[t]{2}{*}{0.52} & \multirow[t]{2}{*}{0.14} \\
\hline (degree) & Female & 36.9 & 8.9 & 37.7 & 8.6 & 38.1 & 10.6 & & & \\
\hline Peak hip extension moment & Male & 3.61 & 2.08 & 3.41 & 1.41 & 3.39 & 1.69 & \multirow[t]{2}{*}{0.57} & \multirow[t]{2}{*}{0.42} & \multirow[t]{2}{*}{0.10} \\
\hline$(\mathrm{N} \cdot \mathrm{m} / \mathrm{kg} \cdot \mathrm{m})$ & Female & 2.68 & 1.71 & 2.22 & 1.36 & 2.56 & 1.56 & & & \\
\hline Peak vertical ground & Male & 2.19 & 0.79 & 2.59 & 1.01 & 2.44 & 1.07 & \multirow[t]{2}{*}{0.54} & \multirow[t]{2}{*}{0.11} & \multirow[t]{2}{*}{0.01} \\
\hline reaction force (BW) & Female & 1.38 & 0.51 & 1.51 & 0.61 & 1.43 & 0.63 & & & \\
\hline
\end{tabular}

BW, body weight; SD, standard deviation.

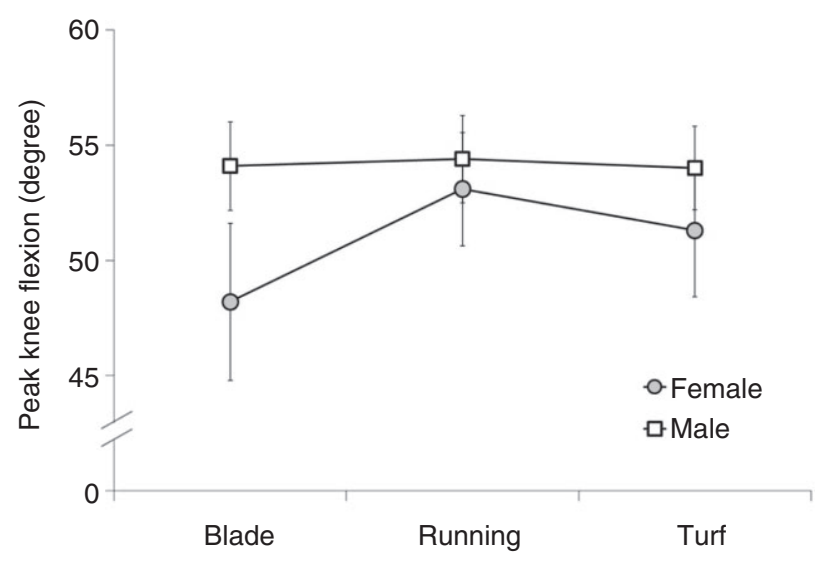

Fig. 6. Interaction of footwear and gender on peak knee flexion during the second landing (mean \pm standard error of the mean).

bited similar amounts of peak dorsiflexion across footwear conditions. There were no statistically significant interactions or main effects for the peak plantarflexion moment.

There was a statistically significant gender by footwear interaction for peak knee flexion (Table 2, Fig. 6, $P=0.05)$ during this landing. The male subjects landed with similar peak knee flexion across all footwear conditions, while the female subjects exhibited a reduced amount of peak knee flexion in the bladed soccer cleat compared with the other footwear conditions. Additionally, there was a gender main effect for the peak knee extension moment during the second landing $(P=0.01$, $\mathrm{ES}=0.99$ ). Female subjects exhibited a $25 \%$ lower peak knee extension moment compared with the male subjects. No interaction or shoe main effects were observed for the peak knee extension moment.
At the hip, both angle and moment values decreased following the peak value until the patients achieved an upright standing posture. No significant interactions or main effects were observed for peak hip flexion or the peak hip extension moment (Table 2).

There were no interactions or main effects for footwear for the peak vertical ground reaction force during the second landing (Table 2). There was, however, a main effect for gender. Female subjects exhibited a $40 \%$ lower peak vertical ground reaction force $(P=0.01$, $\mathrm{ES}=1.26)$ than the male subjects during the second landing.

\section{Discussion}

Lower-extremity injury is a common problem associated with exercise participation and a number of studies are looking into ways to reduce lower-extremity injury (Caraffa et al., 1996; Mandelbaum et al., 2005; Barber-Westin et al., 2009). Because of the effect that footwear has on lower-extremity mechanics, a number of studies have examined the role of footwear in lower-extremity injury. However, to date, few studies have examined the effect that sport-specific footwear has in altering landing (Clarke et al., 1983; Hamill et al., 1992; deKoning \& Nigg, 1994; Perry \& Lafortune, 1995; Brizuela et al., 1997; Smith et al., 2004; Butler et al., 2006, 2007; Cheung \& Ng, 2008; Kong et al., 2009; Morio et al., 2009; Sinclair et al., 2010; Wannop et al., 2010; Oliver et al., 2011). The results of the current study suggest that landing mechanics are affected differently by variations in footwear and gender. In addition, consistent differences in landing mechanics were apparent across the different types of footwear and between the genders. As a result 


\section{Butler et al.}

of this study, it may be beneficial to analyze an individual's landing mechanics in activity-specific footwear.

Significant interactions for gender and footwear were observed at the ankle and knee for the second landing. In the most rigid footwear, female subjects exhibited reduced motion at the ankle and knee when landing following a jump heading task compared with the male subjects. This would suggest that overall, female subjects land with a stiffer lower extremity, which may place greater strain on the connective tissues of the lower extremity (Malinzak, Colby, Kirkendall, Yu, Garrett, 2001; Chappell et al., 2002; Beutler et al., 2009; Weinhandl et al., 2010). The result at the ankle, for the male subjects, supports our initial hypothesis that the bladed cleat would be associated with increased range of motion; however, the result for the female subjects did not support our initial hypothesis. The same hypothesis at the knee was not supported in males or females. Typically, the presence of a firmer surface promotes joint flexion to attenuate the increased load on the lower extremity (Ferris et al., 1998; Kerdok et al., 2002; Smith $\&$ Watanatada, 2002). It was interesting to observe that the females actually went through less range of motion in the stiffer shoe condition. It may be that the stiffer shoe provides less perceived stability for the females and as a result the females go through less joint motion to stabilize the center of mass acceleration. It was also interesting to note that these same interactions, differences in landing mechanics at the ankle and knee, were not apparent when the subjects were asked to land prior to jumping up to head the ball (first landing). This result may suggest that gender and footwear differences in landing mechanics may be influenced by whether or not the landing is followed by an additional jump. The landing followed by the jump heading task may provide an increase in lower-extremity pre-activation, which may provide greater use of the stretch shortening cycle of the lower extremity and place less strain on the passive connective tissues of the lower extremity (DeVita \& Skelly, 1992; Kulas et al., 2006).

The effect of footwear alone was expected to have the largest effect on the mechanics of the ankle and this effect was anticipated to be greatest in the bladed cleat condition. Subjects in the bladed cleat condition landed with increased amounts of dorsiflexion and increased plantarflexion moments during the first landing, which was immediately followed by the jump heading task. This would be expected because the bladed condition provides a stiffer landing surface and as a result, the joint would be expected to go through increased motion to account for the stiff surface in order to normalize the joint loading (Ferris et al., 1998; Kerdok et al., 2002; Smith \& Watanatada, 2002). These combined variables would be expected to place a greater strain on the triceps surae complex as it eccentrically controls dorsiflexion prior to concentrically propelling the center of mass upward during the propulsion phase of the landing (Arner \& Lindholm, 1959). As a result, the relationship between incidence of Achilles tendon pathology and bladed cleat use may be of interest to evaluate. As well, it may be of relevance to examine if this increased amount of dorsiflexion and increased plantarflexion moment is present during other common soccer activities such as running and cutting. It may be that the infrequently elevated load in the bladed cleat would not be indicative of pathological loading; however, further examination into this area is warranted based upon this initial study.

The primary limiting factor in this study was the lack of a standardized jump height that the subjects used for the landing. This is primarily a limitation because of the fact that landing from a standard height is utilized in a large number of studies (Lephart et al., 2002; Hewett et al., 2004, 2006; Ford et al., 2005; Hewett et al., 2005). It could be argued, however, that the use of a body-relative jump distance and jump height for the task created more organic conditions even though they made the results difficult to compare with other studies. Future studies should examine the differences in landing mechanics between the current landing protocol and landing from a standard jump height.

In summary, footwear appears to affect landing mechanics differently between male and female subjects. As a result, it may be appropriate to recommend the screening of sport-specific landing mechanics under sport-specific conditions.

\section{Perspective}

The assessment of landing mechanics is a primary area of focus for intervention programs aimed at reducing lower-extremity injury risk during sport. Prior to this study, it has been assumed that footwear does not play a meaningful role in altering these mechanics. However, the results of this study would suggest that landing mechanics differ based on the footwear as well as the type of landings. The more rigid footwear appears to promote less advantageous landing mechanics in the female population when compared with the male population. These changes are concerning because women consistently exhibit an elevated risk for lowerextremity injuries during sport. As a result of these findings, it is recommended that assessments of sportrelated performance are conducted in the sport-specific footwear that the athlete uses during their typical competition and training. In addition, it may be appropriate to utilize these results in the development of cleated footwear to minimize injury risk while maximizing performance.

Key words: injury prevention, gender, biomechanics, artificial turf, football. 
Effect of soccer footwear on jump landings

\section{References}

Arner O, Lindholm A. Subcutaneous rupture of the Achilles tendon. Acta Chir Scand 1959: 239: 7-51.

Barber-Westin SD, Noyes FR, Smith ST, Campbell TM. Reducing the risk of noncontact anterior cruciate ligament injuries in the female athlete. Phys Sportsmed 2009: 37: 49-61.

Beutler AI, De La Motte SJ, Marshall SW, Padua D, Boden B. Muscle strength and qualitative jump-landing differences in male and female military cadets: the jump-ACL study. J Sports Sci Med 2009: 8: 663-671.

Brizuela G, Llana S, Ferrandis R, García-Belenguer AC. The influence of basketball shoes with increased ankle support on shock attenuation and performance in running and jumping. J Sports Sci 1997: 15: 505-515.

Butler RJ, Davis IS, Hamill J. Interaction of arch type and footwear on running mechanics. Am J Sports Med 2006: 34: 1998-2005.

Butler RJ, Hamill J, Davis I. Effect of footwear on high and low arched runners' mechanics during a prolonged run. Gait Posture 2007: 26: 219-225.

Caraffa A, Cerulli G, Projetti M, Aisa G, Rizzo A. Prevention of anterior cruciate ligament injuries in soccer: a prospective controlled study of proprioceptive training. Knee Surg Sports Traumatol Arthrosc 1996: 4: 19-21.

Chappell JD, Creighton RA, Giuliani C, Yu B, Garrett WE. Kinematics and electromyography of landing preparation in vertical stop-jump: risks for noncontact anterior cruciate ligament injury. Am J Sports Med 2007: 35: 235-241.

Cheung RT, Ng GY. Influence of different footwear on force of landing during running. Phys Ther 2008: 88: 620-628.

Clarke TE, Frederick EC, Hamill CL. The effects of shoe design parameters on rearfoot control in running. Med Sci Sports Exerc 1983: 15: 376-381.

deKoning JJ, Nigg BM. Kinematic factors affecting impact peak vertical ground reaction force in running. $\mathrm{J}$ Biomech 1994: 27: 673.

Devita P, Skelly WA. Effect of landing stiffness on joint kinetics and energetics in the lower extremity. Med Sci Sports Exerc 1992: 24: 108-115.

Ferris DP, Louie M, Farley CT. Running in the real world: adjusting leg stiffness for different surfaces. Proc R Soc Lond B Biol Sci 1998: 265: 989-994.

Ford KR, Myer GD, Smith RL, Byrnes RN, Dopirak SE, Hewett TE. Use of an overhead goal alters vertical jump performance and biomechanics. J Strength Cond Res 2005: 19: 394-399.

Goldman EF, Jones DE. Interventions for preventing hamstring injuries. Cochrane Database Syst Rev 2010 Jan 20: 1: CD006782.

Hamill J, Bates BT, Holt KG. Timing of lower extremity joint actions during treadmill running. Med Sci Sports Exerc 1992: 24: 807-813.

Hennig EM. The influence of soccer shoe design on player performance and injuries. Res Sports Med 2011: 19: 186-201.

Hewett TE, Myer GD, Ford KR. Decrease in neuromuscular control about the knee with maturation in female athletes. J Bone Joint Surg Am 2004: 86: 1601-1608.

Hewett TE, Myer GD, Ford KR, Heidt RS, Colosimo AJ, McLean SG, van denBogert AJ, Paterno MV, Succop P. Biomechanical measures of neuromuscular control and valgus loading of the knee predict anterior cruciate ligament injury risk in female athletes: a prospective study. Am J Sports Med 2005: 33: 492-501.

Hewett TE, Myer GD, Ford KR, Slauterbeck JR. Preparticipation physical examination using a box drop vertical jump test in young athletes: the effects of puberty and sex. Clin J Sport Med 2006: 16: 298-304.

Kerdok A, Biewener AA, McMahon TA, Weyand PG, Herr HM. Energetics and mechanics of human running on surfaces of different stiffnesses. J Appl Physiol 2002: 92: 469-478.

Kong PW, Candelaria NG, Smith DR. Running in new and worn shoes: a comparison of three types of cushioning footwear. Br J Sports Med 2009: 43: 745-749.

Kulas AS, Schmitz RJ, Schultz SJ, Watson MA, Perrin DH. Energy absorption as a predictor of leg impedance in highly trained females. J Appl Biomech 2006: 22: 177-185.

Lephart S, Ferris C, Riemann B. Gender differences in strength and lower extremity kinematics during landing. Clin Orthop Relat Res 2002: 401: 162-169.

Malinzak RA, Colby SM, Kirkendall DT, Yu B, Garrett WE. A comparison of knee joint motion patterns between men and women in selected athletic tasks. Clin Biomech 2001: 16: 438-445.

Mandelbaum BR, Silvers HJ, Watanabe DS, Knarr JF, Thomas SD, Griffin LY, Kirkendall DT, Garrett WE. Effectiveness of a neuromuscular and proprioceptive training program in preventing anterior cruciate ligament injuries in female athletes: 2-year follow up. Am J Sports Med 2005: 33: 1003-1010.

Marshall SW, Guskiewicz KM. Sports and recreational injury: the hidden cost of a healthy lifestyle. Inj Prev 2003: 9: 100-102.

Morio C, Lake MJ, Gueguen N, Rao G, Baly L. The influence of footwear on foot motion during walking and running. J Biomech 2009: 42: 2081-2088.

Myer GD, Chu DA, Brent JL, Hewett TE. Trunk and hip control neuromuscular training for the prevention of knee joint injury. Clin Sports Med 2008: 27: 425-448.

Oliver GD, Stone AJ, Booker JM, Plummer HA. A kinematic and kinetic analysis of drop landings in military boots. J R Army Med Corps 2011: 157: 218-221.

Perry SD, Lafortune MA. Influences of inversion/eversion of the foot upon impact loading during locomotion. Clin Biomech 1995: 10: 253-257.

Queen RM, Abbey AN, Wiegerinck JI, Yoder JC, Nunley JA. Effect of shoe type on plantar pressure: a gender comparison. Gait Posture 2010: 31: 18-22.

Sims EL, Hardaker WM, Queen RM. Gender differences in plantar loading during three soccer-specific tasks. Br J Sports Med 2008: 42: 272-277.

Sinclair J, Bottoms L, Taylor K, Greenhalgh A. Tibial shock measured during the fencing lunge: the influence of footwear. Sports Biomech 2010: 9: 65-71.

Smith G, Watanatada P. Adjustment to vertical displacement and stiffness with changes to running footwear stiffness. Med Sci Sports Exerc 2002: 34: S179.

Smith N, Dyson R, Janaway L. Ground reaction force measures when running in soccer boots and soccer training shoes on a natural turf surface. Sports Eng 2004: 3: 159-167.

van Gent RN, Siem D, van Middelkoop M, van Os AG, Bierma-Zeinstra SM, Koes BW. Incidence and determinants of lower extremity running injuries in long distance runners: a systematic review. Br J Sports Med 2007: 41: 469-480.

Wannop JW, Worobets JT, Stefanyshyn DJ. Footwear traction and lower extremity joint loading. Am J Sports Med 2010: 38: 1221-1228.

Weinhandl JT, Joshi M, O'Connor KM. Gender comparisons between unilateral and bilateral landings. J Appl Biomech 2010: 26: 444-453. 